\title{
EXPERIMENTAL VERIFICATION OF NUMERICAL OPTIMIZATION OF A PLUNGER FOR GLASS PRESSING
}

\author{
Petr SALAČ, Václav DVOŘÁK*
}

\begin{abstract}
The main aim of these experiments is to verify the results of numerical optimization described in [1], [2], [3] and [4]. The results of measuring the classical plunger with its drilled internal cavity and the optimized plunger with its sparked-out inner cavity and applied flow control body are presented in this article. The temperature distributions across both plunger surfaces are estimated by values measured at four points placed 5 millimetres under the plunger surfaces.
\end{abstract}

\section{INTRODUCTION}

Two main problems appear during glass pressing on the surface of a moulded piece. If the surface of the plunger is too hot at the moment of separation of the moulded piece and the plunger, then the glass melt adheres to the device and deformation of the moulded piece follows. Conversely, if the surface of the plunger is too cold, then small fire cracks appear on the surface of the moulded piece, which means poorer quality of production. For these reasons, it is convenient to achieve a constant distribution of temperature across the surface of the moulding device at the moment of separation of the plunger from the moulded piece.

\section{Formulation of the PROBlem}

We consider the union of four planar regions $\Omega=\Omega_{0} \cup \Omega_{1} \cup \Omega_{2} \cup \Omega_{3}$, which represents a planar cross section of the system mould, glass, plunger, canal of the plunger and flow control body.

Region $\Omega_{0}$ represents the plunger, region $\Omega_{1}$ a cooled glass piece, region $\Omega_{2}$ the cooling canal inside the plunger, where cooling water flows, and region $\Omega_{3}$ represents the mould. Furthermore, we denote $\Gamma_{1}$ as the boundary between plunger $\Omega_{0}$ and moulded piece $\Omega_{1}$ and $\Gamma_{2}$ as the boundary between plunger $\Omega_{0}$ and plunger cavity $\Omega_{2}$. $\Gamma_{2}$ has a shape received as a result of the optimization problem described in [3]. We denote $\Gamma_{3}$ as part of the boundary connecting the system mould, moulded piece and plunger with presser, $\Gamma_{4}$ part of the axis of symmetry, $\Gamma_{5}$ part of the boundary formed by the outward surface of the flow control body, which has a shape which it received as a result of the second step of the optimization problem described in [4]. $\Gamma_{6}$ is the denotation for part of the boundary between moulded piece $\Omega_{1}$ and mould $\Omega_{3}$ and $\Gamma_{7}$ is the outward boundary of the mould, which is surrounded by an external environment.

*RNDr. Petr Salač, CSc., Technical University of Liberec, Department of Mathematics and Didactics of Mathematics, Studentská 2, Liberec 1, 461 17, petr.salac@tul.cz

Doc. Ing. Václav Dvořák, Ph.D., Technical University of Liberec, Department of Power Engineering Equipment, Studentská 2, Liberec 1, 461 17, vaclav.dvorak@tul.cz

This is an Open Access article distributed under the terms of the Creative Commons Attribution License 2.0, which permits unrestricted use, distribution, and reproduction in any medium, provided the original work is properly cited. 


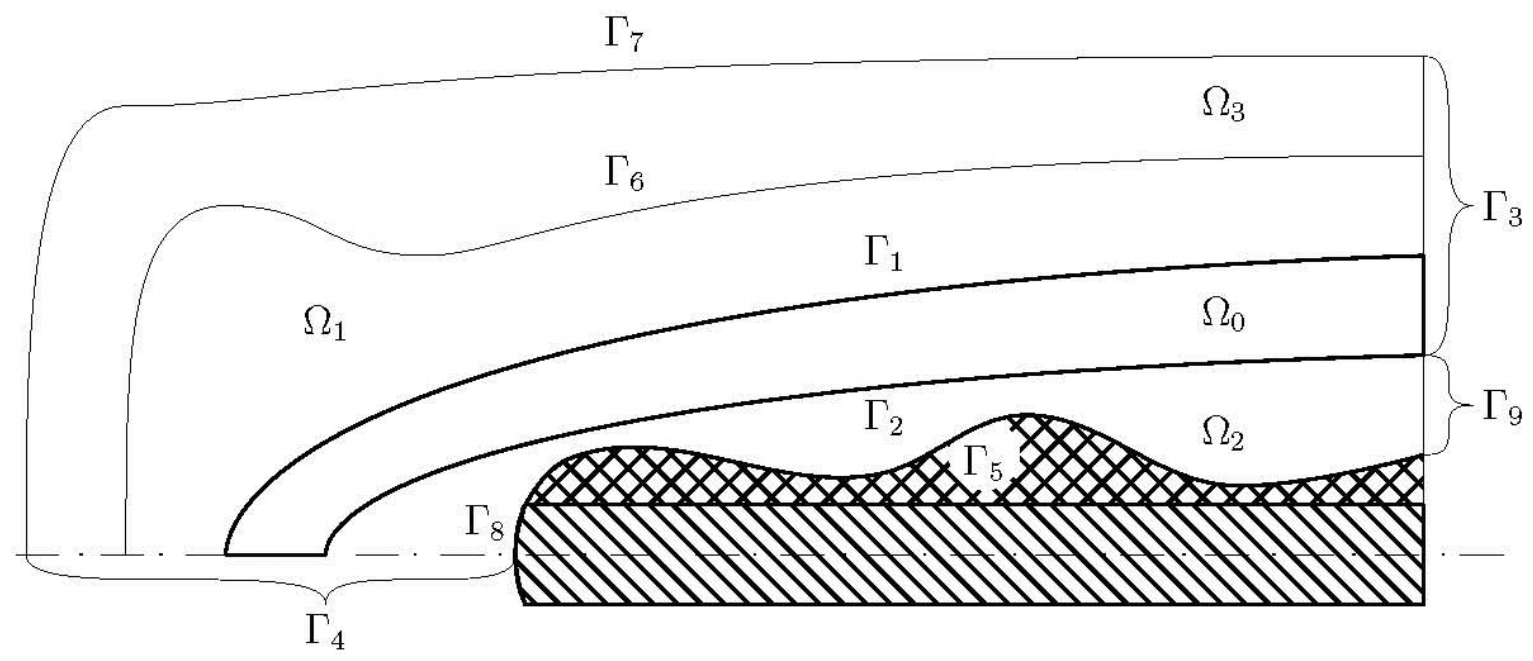

Fig. 1 Scheme of the system mould, glass piece, plunger, canal of plunger and flow control body.

$\Gamma_{8}$ denotes part of the boundary where cooling water comes into the cooling canal of the plunger, and $\Gamma_{9}$ part of the boundary where water exits.

In the regions $\Omega_{0}$ (plunger) and $\Omega_{3}$ (mould), the conduction of heat without an inner heat source is described by the equation

$$
-\frac{k}{\varrho} \Delta \vartheta=0 .
$$

In the region $\Omega_{1}$ (glass piece), we use the equation for the conduction of heat with inner heat source $q_{1}$ in the form

$$
-\frac{k}{\varrho} \Delta \vartheta=q_{1} .
$$

In the region $\Omega_{2}$ (plunger canal in which flows cooling water) the conduction of heat is described by the energy equation in the form

$$
c_{v} \operatorname{grad} \vartheta \cdot \boldsymbol{u}-\frac{k}{\varrho} \Delta \vartheta=2 v|D(\boldsymbol{u})|^{2},
$$

where $\vartheta$ denotes temperature on the absolute temperature scale and $\boldsymbol{u}$ is the velocity of flowing water satisfying the equation of continuity

$$
\operatorname{div} \boldsymbol{u}=0
$$

and Navier-Stokes equation in the form

$$
\boldsymbol{u} \text {. } \operatorname{grad} \boldsymbol{u}-\frac{\mu}{\varrho} \Delta \boldsymbol{u}=\boldsymbol{f}-\frac{1}{\varrho} \operatorname{grad} p .
$$

In the model we assume transit conditions for contact between two bodies, where one of them changes its mass because of the influence of solidification, on boundaries $\Gamma_{1}$ and $\Gamma_{6}$, respectively, in the form

and

$$
\left(k_{1} \frac{\partial \vartheta_{1}}{\partial n}\right)^{+}-\left(k_{0} \frac{\partial \vartheta_{0}}{\partial n}\right)^{-}=\beta_{1} \quad \text { on } \Gamma_{1}
$$

$$
\left(k_{1} \frac{\partial \vartheta_{1}}{\partial n}\right)^{+}-\left(k_{3} \frac{\partial \vartheta_{3}}{\partial n}\right)^{-}=\beta_{6} \quad \text { on } \Gamma_{6} \text {. }
$$

The boundary conditions of the third type for contact between a body and its environment at boundaries $\Gamma_{2}$ and $\Gamma_{7}$, respectively, are

and

$$
-\left(k_{0} \frac{\partial \vartheta_{0}}{\partial n}\right)^{-}=\alpha\left(\left.\vartheta_{0}\right|_{\Gamma_{2}}-\left.\vartheta_{2}\right|_{\Gamma_{2}}\right) \quad \text { on } \Gamma_{2}
$$

$$
-\left(k_{3} \frac{\partial \vartheta_{3}}{\partial n}\right)^{-}=\alpha\left(\left.\vartheta_{3}\right|_{\Gamma_{7}}-\vartheta_{4}\right) \quad \text { on } \Gamma_{7} \text {, }
$$

where $\vartheta_{i}$ denotes temperature in $\Omega_{i}(i=0,2,3)$ and $\vartheta_{4}$ the temperature of the environment. 
In article [3] the problems of shape optimization were formulated, where the shape of boundary $\Gamma_{2}$ and $\Gamma_{5}$, respectively, such that the cost functional

and

$$
\mathfrak{J}^{S}\left(\Gamma_{2}\right)=\left\|\left.\vartheta\left(\Gamma_{2}\right)\right|_{\Gamma_{1}}-K\right\|_{0, r, \Gamma_{1}}^{2}
$$

$$
\mathfrak{J}^{P}\left(\Gamma_{5}\right)=\left\|\left.\vartheta\left(\Gamma_{5}\right)\right|_{\Gamma_{1}}-K\right\|_{0, r, \Gamma_{1}}^{2}
$$

take the minimum value of the set of admissible design functions.

The experiment suggested itself as a result of the numerical results of optimization problems. The distribution of temperature in the classical plunger with a drilled internal cavity was compared with the distribution of temperature in the optimized plunger with its sparked-out inner cavity and applied flow control body. For details see the article of M. Stary [5], where the course of the experiment with a detailed description of the testing equipment are described.

Measurements were evaluated at four points placed 5 millimetres below the surface. Point B1 is located on the lower end of the axis of the plunger ( $5 \mathrm{~mm}$ below the surface), point B4 at a distance of 50 millimetres above a plane perpendicular to the plunger axis and level with the vertex, point B7 at a distance of 125 millimetres (from the aforementioned plane) and point B10 at a distance of 200 millimetres.

B1

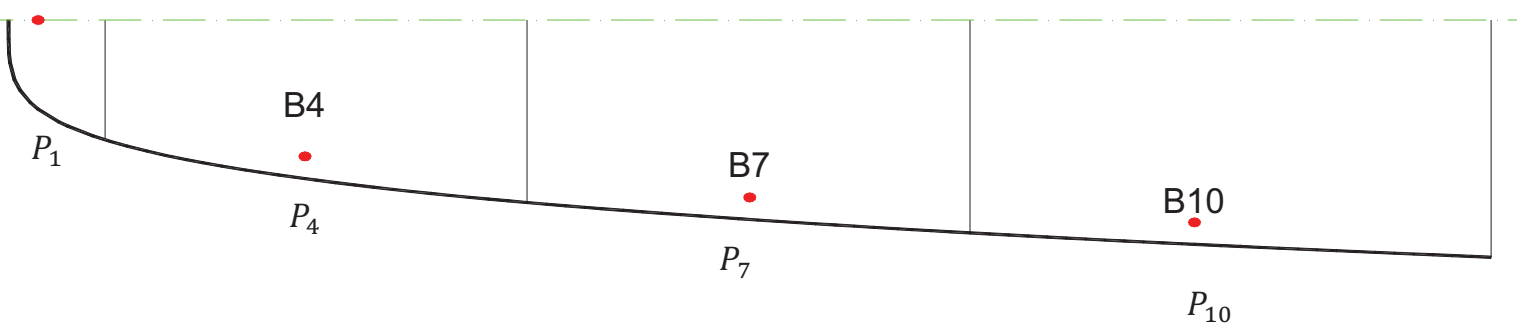

Fig. 2 Schema of the location of measurement points with areas corresponding to each point.

\begin{tabular}{|l|c|c|c|c|l|}
\hline Surface corresponding to point $\mathrm{Bi}$ & $P_{1}$ & $P_{4}$ & $P_{7}$ & $P_{10}$ & Total $P$ \\
\hline Area of corresponding surface $\left[\mathrm{m}^{2}\right]$ & 0,003 & 0,016 & 0,021 & 0,029 & 0,069 \\
\hline
\end{tabular}

Tab. 1 Areas of surfaces corresponding to single measurement points.

The results of five measurements of the original plunger construction (Plunger I) and the results of five measurements of the plunger with the optimized cooling cavity and applied flow control body (Plunger II) are summarized in tab. 2. Stagnation temperatures after six hours at these points are in the first four lines, the range of measured temperatures is on the fifth line.

The average temperatures computed as a weighted arithmetical mean

$$
\bar{\vartheta}_{l}=\frac{1}{P}\left(\vartheta_{1} \cdot P_{1}+\vartheta_{4} \cdot P_{4}+\vartheta_{7} \cdot P_{7}+\vartheta_{10} \cdot P_{10}\right),
$$

where the weights are areas of surfaces corresponding to single measurement points (see fig. 2 and tab. 1), are on the sixth line of tab. 2.

The arithmetical mean of average temperatures from five measurements

is introduced in the seventh line.

$$
\mathbf{K}=\frac{\sum_{i=1}^{5} \overline{\vartheta_{1}}}{5}
$$

In the last line of tab. 2, the numerical approximation of cost functional (11) in the form

is computed.

$$
\Im^{E x p}=\left(\vartheta_{B 1}-K\right)^{2} \cdot P_{1}+\left(\vartheta_{B 4}-K\right)^{2} \cdot P_{4}+\left(\vartheta_{B 7}-K\right)^{2} \cdot P_{7}+\left(\vartheta_{B 10}-K\right)^{2} \cdot P_{10}
$$




\begin{tabular}{|l|l|l|l|l|l|l|l|l|l|l|}
\hline & \multicolumn{1}{|l}{ Plunger I } & \multicolumn{1}{l|}{ llunger II } \\
\hline Experiment & 1. & 2. & 3. & 4. & 5. & 1. & 2. & 3. & 4. & 5. \\
\hline$\vartheta_{B 1}\left[{ }^{\circ} \mathrm{C}\right]$ & 113,4 & 113,3 & 113,0 & 112,9 & 112,5 & 108,9 & 105,1 & 104,7 & 105,8 & 101,7 \\
\hline$\vartheta_{B 4}\left[{ }^{\circ} \mathrm{C}\right]$ & 104,3 & 105,8 & 106,8 & 106,1 & 106,2 & 105,0 & 102,2 & 103,1 & 104,7 & 100,7 \\
\hline$\vartheta_{B 7}\left[{ }^{\circ} \mathrm{C}\right]$ & 101,9 & 99,3 & 100,0 & 98,7 & 98,2 & 109,5 & 107,9 & 109,3 & 109,1 & 107,8 \\
\hline$\vartheta_{B 10}\left[{ }^{\circ} \mathrm{C}\right]$ & 96,7 & 96,2 & 96,9 & 95,7 & 95,0 & 105,9 & 105,2 & 106,6 & 105,5 & 104,9 \\
\hline \hline$\Delta_{\max }\left[{ }^{\circ} \mathrm{C}\right]$ & $\mathbf{1 6 , 7}$ & $\mathbf{1 7 , 1}$ & $\mathbf{1 6 , 1}$ & $\mathbf{1 7 , 2}$ & $\mathbf{1 7 , 5}$ & $\mathbf{4 , 5}$ & $\mathbf{5 , 7}$ & $\mathbf{6 , 2}$ & $\mathbf{4 , 4}$ & $\mathbf{7 , 1}$ \\
\hline \hline $\bar{\vartheta}_{1}$ & 100,8 & 100,1 & 100,8 & 99,8 & 99,3 & 106,9 & 105,3 & 106,5 & 106,4 & 104,7 \\
\hline $\mathbf{K}$ & \multicolumn{9}{|c|}{100,2} \\
\hline$\Im^{E x p}$ & $\mathbf{1 , 2 1}$ & $\mathbf{1 , 5 0}$ & $\mathbf{1 , 5 1}$ & $\mathbf{1 , 6 7}$ & $\mathbf{1 , 8 9}$ & $\mathbf{0 , 3 0}$ & $\mathbf{0 , 3 3}$ & $\mathbf{0 , 3 8}$ & $\mathbf{0 , 2 4}$ & $\mathbf{0 , 6 0}$ \\
\hline
\end{tabular}

Tab. 2 Stagnation temperatures for 5 experiments for each plunger.

The main target of the conducted optimization was to achieve uniform temperature across the entire surface of the plunger.

We are testing the null hypothesis about the correspondence of mean values of the outputs of the cost functional of experimental data obtained from both plungers against the alternative, namely, that the mean value of the outputs of the cost functional on the optimized plunger is statistically significantly less than the mean value of the outputs of the cost functional from the original plunger. We denote $\mu_{1}$ the mean value of outputs of the cost functional $\mathfrak{\Im}^{E x p}$ on plunger I and $\mu_{2}$ the mean value of outputs of $\mathfrak{\Im}^{E x p}$ on plunger II.

A single tail test about the correspondence of mean values was used, so

$$
\begin{aligned}
& \mathrm{H}_{0}: \mu_{1}=\mu_{2}, \\
& \mathrm{H}_{1}: \mu_{1}>\mu_{2} .
\end{aligned}
$$

Testing statistic

$$
T=\frac{\overline{\Im_{1}^{E x p}}-\overline{\Im_{2}^{E x p}}}{\sqrt{\frac{\left(n_{1}-1\right) \cdot s_{1}^{2}+\left(n_{2}-1\right) \cdot s_{2}^{2}}{n_{1}+n_{2}-2}} \sqrt{\frac{1}{n_{1}}+\frac{1}{n_{2}}}}=3,9857,
$$

where $\overline{\mathfrak{J}_{1}^{E x p}}$ and $\overline{\widetilde{J}_{2}^{E x p}}$, respectively, denote the arithmetical average of data from sample 1 and sample 2, $\mathrm{n}_{1}$ and $\mathrm{n}_{2}$ the size of sample 1 and sample $2, \mathrm{~s}_{1}^{2}$ and $\mathrm{s}_{2}^{2}$ the standard deviation of data from sample 1 and sample 2 .

\section{CONCLUSION}

The results allow us to reject the null hypothesis even at significance level $a=0,005$. That means that we can say with $99,5 \%$ probability that the results obtained from plunger II are better than the results obtained from plunger I.

We can calculate a $95 \%$ confidence interval for the difference of mean values $\mu_{1}-\mu_{2}$ in the form $(0,821 ; 1,514)$. This allows us to say that the mean value $\mu_{2}$ is about 0,821 less than the mean value $\mu_{1}$ with a probability of $97,5 \%$.

\section{ACKNOWLEDGEMENT}

This work was supported by the Research plan No. MSM 4674788501 funded by Ministry of Education, Youth and Sports of the Czech Republic. 


\section{REFERENCES}

[1] Salač P.: Modelling of heat flow in glass forming, Sborník $z$ 16. Semináře, Moderní matematické metody v inženýrství, Dolní Lomná, 2007, pages 262-265

[2] Salač P.: Problem of shape optimization of cooling canal of the plunger in glass forming, Sborník z 17. Semináře, Moderní matematické metody v inženýrství, Dolní Lomná, 2008, pages 177 - 181

[3] Salač P.: Shape optimization of area with cooling medium, Sborník z 18. Semináře, Moderní matematické metody v inženýrství, Dolní Lomná, 2009, pages $207-211$

[4] Salač P., Dvořák V.: Shape optimization of axially symmetric through cooling canal, $25^{\text {th }}$ conference with international participation Computational Mechanics 2009, Hrad Nečtiny, Czech Republic, ISBN 978-80-7043-824-4 (CD)

[5] Starý M.: Physical modelling of plunger for glass forming, International conference, Experimental fluid mechanics 2010, 2010 